\title{
Usulan Kinerja Green Logistic dengan Pendekatan Root Cause Analysis guna Meningkatkan Re-Order Point yang Efektif
}

\section{Lolyka Dewi Indrasari ${ }^{1}$, Ana Komari ${ }^{2}$ dan Saufik Luthfianto ${ }^{3}$}

${ }^{1,2}$ Program Studi Teknik Industri, Universitas Kadiri, Pojok, Kec. Mojoroto, Kediri, Jawa Timur 64115 ${ }^{3}$ Program Studi Teknik Industri, Universitas Pancasakti Tegal, Jl. Halmahera No.KM, Mintaragen, Kec. Tegal Tim., Kota Tegal, Jawa Tengah 52121

Correspondence: lolyka@unik-kediri.ac.id (+62 812-5279-5715)

Received: $D D M M Y Y$ - Revised: $D D M M Y Y$ - Accepted: $D D M M Y Y$ - Published: $D D M M Y Y$

\begin{abstract}
Abstrak. Konsep manajemen persediaan akan dipuncakkan untuk mencapai green logistic. Pertumbuhan ekonomi mengakibatkan perusahaan manufaktur harus menerapkan efisiensi yang ramah lingkungan. Efisiensi ramah lingkungan tidak hanya fokus pada lingkungan sekitar perusahaan. Efisiensi ramah lingkungan menggunakan pendekatan Green Logistic demi mencapai kinerja optimal. Green logistic sebagai puncak akhir pencapaian dalam konsep manajemen persediaan. Tujuan penelitian 1) untuk membandingkan nilai pemesanan kembali secara eksisting dengan metode Re-Order Point pada Preform Clear 600 ml, 2) untuk meningkatkan peran Green Logistic pada Preform Clear $600 \mathrm{ml}$. Metode analisis data diawali dengan mengitung nilai $R e-$ Order Point dibandingkan dengan kondisi pemesanan secara eksisting. Tahap kedua menggunakan metode FMEA untuk mengetahui indikator dengan nilai RPN tertinggi ranking 1, 2 dan 3. Tahap ketiga membuat diagram fishbone dengan melakukan brainstroming untuk mengetahui usulan yang tepat dalam mencapai green logistic. Penelitian ini menghasilkan bahwa perbandingan nilai pemesanan kembali secara eksisting sebesar 2.000.000 buah preform $600 \mathrm{ml}$ sedangkan metode Re-Order Point sebesar 2.284.174 pada Preform Clear 600 ml, sehingga efektifitas laba dengan acuan Re-Order Point lebih menguntungkan, 2) Peran Green Logistic pada Preform Clear $600 \mathrm{ml}$ dengan usulan pengembangan Monitoring dan pelatihan pekerja di bidang logistik perlu di tingkatkan 1 bulan, evaluasi persediaan lebih baik menerapkan metode analisis Re - Order Point dan meningkatkan jadwal kedatangan preform $600 \mathrm{ml}$ dengan langkah meeting pra- kedatangan preform $600 \mathrm{ml}$.
\end{abstract}

Kata kunci: Green, Logistic, Preform, RPN, Re- order point

Citation Format: Indrasari, D. L., Komari, A. \& Luthfianto, S. (2021). Usulan Kinerja Green Logistic dengan Pendekatan Root Cause Analysis guna meningkatkan Re-Order Point yang Efektif, 2021, 4458 . 


\section{PENDAHULUAN}

Manajemen persediaan sebagai faktor utama dalam mencapai nilai persediaan yang efektif. Nilai persediaan menggunakan puncak Re-Order Point sebagai pemesanan kembali di masa mendatang. Pemesanan kembali harus diperhitungan dengan optimum. Konsep pemesanan kembali sebagai bukti, bahwa persediaan yang ada di gudang harus mengalami pemindahan. Pemindahan ini sebagai pergerakan untuk memberikan nilai logistik yang baik. Nilai logistik sebagai acuan laba yang dinamis dalam perusahaan. Logistik sangat berkaitan dengan lingkungan. Dominan perusahaan manufaktur mengabaikan lingkungan. Pengabaian ini menyebabkan masalah yang bertentangan dengan ISO 14000 (Indrasari et al., 2014). Oleh sebab itu, penilaian $R e$-Order Point perusahaan tidak lepas dengan penilaian logistik yang ramah lingkungan. Re-Order Point adalah salah satu dari konsep Economic Order Quantity (Hertini et al., 2018). Penelitian ini membuat analisis Re-Order Point secara mandiri yang terintegrasi dengan FMEA dan Fishbone Diagram (Waisul et al., 2017).

Konsep manajemen persediaan akan dipuncakkan untuk mencapai green logistic (Prokop, 2011). Pertumbuhan ekonomi mengakibatkan perusahaan manufaktur harus menerapkan efisiensi yang ramah lingkungan. Efisiensi ramah lingkungan tidak hanya fokus pada lingkungan sekitar perusahaan. Efisiensi ramah lingkungan menggunakan pendekatan Green Logistic demi mencapai kinerja optimal (Seroka-Stolka, 2014). Green logistic sebagai puncak akhir pencapaian dalam konsep manajemen persediaan (Trivellas et al., 2020).

Permasalahan yang terjadi pada Perusahaan $\mathrm{X}$ yang bergerak dibidang minuman, fokus pada preform $600 \mathrm{ml}$. Preform $600 \mathrm{ml}$ adalah wadah botol untuk minuman bersoda yang diproduksi oleh Perusahaan X. Kendala yang sedang dihadapi adalah proses pemesanan kembali disetiap periode selalu konstan. Pemesanan kembali secara konstan tidak dapat meningkatkan laba perusahaan. Pemesanan preform $600 \mathrm{ml}$ dari waktu ke waktu sebesar 2.000.000 buah. Nilai pemesanan ini sebagai langkah aman untuk menghindari terjadinya kerugian anggaran. Tetapi, juga sebagai cara tidak kemampuan untuk meningkatkan laba perusahaan. Oleh sebab itu, pemesanan kembali diharapkan mampu di optimalkan dengan kinerja Re - Order Point yang terintegrasi dengan Green Logistic.

$R e-O r d e r$ point berfungsi sebagai titik pemesanan kembali dimasa mendatang agar lebih optimum (Umry \& Singgih, 2019). Green logistic sebagai upaya memberikan kinerja yang lebih baik dari kondisi sebelumnya. 
Penelitian (Hudori, 2018), menyatakan penggunaan Re - Order Point sebagai pengendalian persediaan yang efektif dimasa mendatang. Re - Order Point untuk memonitoring persediaan di saat persediaan sedang tidak sesuai di masa saat ini.

Penelitian (Mangla et al., 2018), menyatakan rantai pasokan dan logistik hijau memiliki peran penting dalam optimasi persediaan di gudang. Penilaian skor tertinggi FMEA mengenai adopsi logistik hijau yang dapat memberikan motivasi, pengembangan program dan cara kerja secara ramah lingkungan organisasi.

Penelitian (Indrasari et al., 2014), menyatakan bahwa implementasi Green Logistic guna meningkatan ISO 14000, standart dalam pemilihan penyimpanan, Perusahaan menggunakan alat angkut ramah lingkungan, standart pengiriman sesuai jadwal yang diminta, daya tampung gudang yang memenuhi kapasitas barang yang dikembangkan lebih lanjut dengan menyusun Standard Operation Prosedure (SOP) sebagai pelaksanaan strategi yang diusulkan.

Penelitian ini menggunakan metode $R e$-Order Point untuk meningkatkan efisiensi persediaan dimasa mendatang. FMEA untuk memberikan ranking pada masalah serius dalam persediaan. Kedua metode analisis ini juga menggunakan fishbone diagram guna mengenai akar masalah yang dapat diusulkan sebagai pengembangan green logistic (Anik Satria Dewi et al., 2016).

Rumusan masalah penelitian ini 1) bagaimana membandingkan nilai pemesanan kembali secara eksisting dengan metode Re-Order Point pada Preform Clear $600 \mathrm{ml}$ ?, 2) Bagaimana langkah dalam untuk meningkatkan peran Green Logistic pada Preform Clear $600 \mathrm{ml}$ ?.

Tujuan penelitian ini 1) untuk membandingkan nilai pemesanan kembali secara eksisting dengan metode Re-Order Point pada Preform Clear $600 \mathrm{ml}$, 2) untuk meningkatkan peran Green Logistic pada Preform Clear $600 \mathrm{ml}$.

\section{TINJAUAN PUSTAKA}

\section{A. Green Logistic}

Green logistic guna mengurangi biaya, kehandalan layanan, termasuk fleksibilitas, dan efisiensi persediaan yang tepat (Indrasari et al., 2014). Perusahaan yang terlibat dalam distribusi memungkinkan implementasi secara berkelanjutan.

\section{B. Manajemen Persediaan}

Manajemen persediaan adalah produk yang disimpan untuk memenuhi tujuan proses produksi maupun distribusi (Indrasari, 2020). Kegiatan utama yang dilakukan dalam 
manajemen persediaan untuk periode berjalan, memastikan persediaan dikelola dengan optimal, dan efisiensi dalam arti dapat memperkecil biaya persediaan (Ivanov et al., 2017).

\section{Re-Order Point}

Re - Order Point adalah salah satu manajemen persediaan yang memiliki tujuan utama untuk meminimalisir atau menekan terjadinya situasi kehabisan persediaan (Nobil et al., 2020). Re - Order Point adalah suatu titik yang mana suatu barang di dalam gudang harus ditambah lagi persediaannya sebelum mengalami kehabisan persediaan. Re - Order Point sebagai titik yang mana suatu barang di dalam gudang harus ditambah persediaannya sebelum mengalami kehabisan persediaan (Hamdy \& Masari, 2020).

\section{Kegagalan Produk}

\section{FMEA}

Failure Mode and Effect Analysis (FMEA) sebagai pendekatan sistematik untuk proses mengidentifikasi mode kegagalan potensial dan efeknya (Nugroho, 2017). FMEA berdasarkan dampak yang diberikan terhadap kesuksesan suatu misi dari sebuah sistem (Badariah et al., 2012).

\section{Fishbone Diagram}

Diagram Fishbone adalah sebuah diagram yang digunakan untuk mengidentifikasi berbagai penyebab dari sebuah kejadian atau proses (Fachry Hafid \& Muh Syukur Yusuf, 2018). Fishbone diagram akan mengidentifikasi berbagai sebab potensial dari satu efek atau masalah, dan menganalisis masalah tersebut melalui sesi brainstorming. Masalah akan dipecah menjadi sejumlah kategori yang berkaitan, mencakup manusia, material, mesin, prosedur, kebijakan, dan sebagainya. Setiap kategori mempunyai sebab-sebab yang perlu diuraikan melalui sesi brainstorming.

\section{METODOLOGI PENELITIAN}

Lokasi penelitian adalah PT. Wira Akasha International, Tbk Sengon Plant. Penelitian sejak Juli 2021. Penelitian ini dengan jenis kuantitatif yang menggambarkan pengolahan data menggunakan alat metode Re-Order Point dan FMEA. Jenis data penelitian ini adalah data primer. Data primer sebagai data yang diolah menggunakan kedua metode tersebut. Data primer adalah persediaan Preform Clear $600 \mathrm{ml}$ pada bulan Agustus 2020 Juli 2021.

Pengumpulan data diawali dengan observasi lapangan dipandu oleh manajer logistik. Tahap observasi sebagai awal pengenalan mengenai data primer yang digunakan dalam 
penelitian. Tahap wawancara dilakukan untuk mengetahui kondisi eksisting manajemen persediaan produk dalam masa 12 bulan yang lalu. Kondisi eksisting pemesanan kembali akan dibandingkan dengan alat metode analisis Re-Order Point dan di evaluasi menggunakan alat metode analisis FMEA dan Fishbone Diagram untuk mencapai Green Logistic. Metode analisis data penelitian dengan tahapan berikut:

\subsection{Re-Order Point}

Pemesanan kembali menggunakan metode analisis Re-Order Point dengan rumus sebagai berikut (Hamdy \& Masari, 2020):

$$
R O P=\bar{D} \cdot[L T+S S]
$$

Penilaian $\bar{D}$ adalah rata - rata permintaan. Rumus $\bar{D}$ adalah $\bar{D}=\frac{D=\sum_{n=1}^{n=1} D}{n}$. Penilaian $D$ adalah total biaya permintaan (Rp). Penilaian LT digunakan untuk mengetahui rata- rata waktu tunggu persediaan (hari). Penilaian LT $=\left(\overline{L T} \cdot \frac{n_{m}}{n_{d}}\right)$, Penilaian $n_{m}$ adalah jumlah bulan yang digunakan dalam permintaan (12 bulan), penilaian $n_{d}$ adalah jumlah hari kerja dalam satu tahun (300 hari). Penilaian (SS) untuk menghitung Safety Stock dengan penilaian $S S=1,65 . \sigma$.

\subsection{Perbandingan Kondisi Eksisting Perusahaan dan Metode Re-Order Point}

Hasil pengolahan data diharapkan lebih efektif menggunakan metode Re-Order Point. Berarti Re-Order Point (Rp) > Kondisi Eksisting (Rp).

\subsection{FMEA}

Penggunaan FMEA menggunakan kriteria Risk Priority Number (RPN), dengan faktor Severity (S), Occurrence (O) dan Detection (D) (Sutrisno \& Lee, 2011). Persamaan rumus yang digunakan adalah (Braaksma, 2012):

$$
\mathrm{RPN}=\mathrm{S} \times \mathrm{O} \times \mathrm{D}
$$

\subsection{Fishbone Diagram}

Penilaian Fishbone Diagram dengan mengetahui faktor yang menyebabkan Kondisi Eksisting (Rp) tidak sesuai harapan dari metode Re-Order Point. Faktor Function Failure ranking 1, 2 dan 3 dari FMEA akan diidentifikasi menggunakan Equipment, Process, People, Materials, Environment dan Management. 


\section{HASIL DAN PEMBAHASAN}

Berdasarkan tujuan penelitian yang telah dijelaskan. Hasil perhitungan Re-Order Point mengacu pada tahapan pengolahan data. Pengolahan diawali dengan acuan data permintaan yang berasal dari data primer, sebagai berikut.

Tabel 1. Persediaan Preform $600 \mathrm{ml}$ (gross)

\begin{tabular}{cccc}
\hline Indeks Waktu & $\begin{array}{c}\text { Harga Pembelian } \\
(\mathrm{Rp})\end{array}$ & $\begin{array}{c}\text { Permintaan } \\
\text { (gross) }\end{array}$ & Jumlah (Rp) \\
\hline Agustus 2020 & 123.840 & 161 & 19.902 .147 \\
September 2020 & 123.840 & 179 & 22.113 .497 \\
Oktober 2020 & 123.840 & 175 & 21.622 .086 \\
November 2020 & 123.840 & 173 & 21.376 .381 \\
Desember 2020 & 123.840 & 218 & 27.027 .608 \\
Januari 2021 & 123.840 & 222 & 27.519 .019 \\
Februari 2021 & 123.840 & 173 & 21.376 .381 \\
Maret 2021 & 123.840 & 165 & 20.393 .558 \\
April 2021 & 123.840 & 214 & 26.536 .197 \\
Mei 2021 & 123.840 & 175 & 21.622 .086 \\
Juni 2021 & 123.840 & 169 & 20.884 .970 \\
Juli 2021 & 123.840 & 169 & 20.884 .970 \\
Total (gross) & 1.486 .080 & 2.190 & 271.258 .898 \\
Rerata (gross) & 123.840 & 183 & 22.604 .908 \\
\hline
\end{tabular}

(Sumber: Data Primer, 2021)

Tabel 1, menunjukkan persediaan preform 600 ml sejak Agustus 2020 - Juli 2021 yang akan digunakan untuk mengukur Re - Order Point. Harga Pembelian dengan total sebesar Rp. 1.486.080 per gross. Nilai permintaan dari suplier sebesar 2.190 gross dan jumlah nilai persediaan Rp. 271.258.898.

Tabel 2. Biaya Sekali Pesan

\begin{tabular}{ccr}
\hline Gross & Jenis & Biaya (Rp) \\
\hline \multirow{3}{*}{ Preform $600 \mathrm{ml}$} & Operasional & 50.000 \\
& Administrasi & 100.000 \\
& Darurat & 300.000 \\
Jumlah Biaya (Rp) & 100.000 \\
& Packing & 550.000 \\
\hline
\end{tabular}

(Sumber: Data Primer, 2021)

Tabel 2, menunjukkan biaya sekali pesan untuk preform $600 \mathrm{ml}$ sebesar Rp. 550.000,-. Biaya sekali pesan ini dilakukan sekali setiap terjadi pemesanan. Pemesanan preform $600 \mathrm{ml}$ dengan jenis kriteria operasional sebesar Rp. 50.000, administrasi sebesar Rp. 100.000, darurat sebesar Rp. 300.000 dan packing sebesar Rp. 100.000. 
Tabel 3. Faktor Biaya Penyimpanan

\begin{tabular}{ccc}
\hline Suku Bank & $10 \%$ & Pertahun \\
\hline Depresiasi & $0,50 \%$ & per unit \\
Total & $10,5 \%$ & pertahun \\
Rerata & 183 & Gross
\end{tabular}

(Sumber: Data Primer, 2021)

Tabel 3, biaya penyimpanan menggunakan suku bunga $10 \%$ setiap tahun, nilai depresiasi per gross sebesar 0,50\%. Sehingga, rata - rata pengadaan preform $600 \mathrm{ml}$ menggunakan faktor biaya penyimpanan sebesar $10,5 \%$ setiap tahun.

Tabel 4. Biaya Penyimpanan Per Gross

\begin{tabular}{cccc}
\hline No & Jenis & Biaya Permintaan $(\mathrm{Rp})$ & Biaya Simpan/gross $(\mathrm{Rp})$ \\
\hline 1 & Preform $600 \mathrm{ml}$ (gross) & 271.258 .898 & 2.373 .515 \\
\hline
\end{tabular}

(Sumber: Olah Data Primer, 2021)

Tabel 4, menunjukkan biaya penyimpanan per gross preform $600 \mathrm{ml}$ sebesar Rp. 2.373.515. Biaya permintaan selama 12 bulan sebesar Rp. 271.258.898.

Tabel 5. Waktu Tunggu Pemesanan

\begin{tabular}{ccc}
\hline No & Jenis & Waktu Tunggu (hari) \\
\hline 1 & Preform $600 \mathrm{ml}$ (gross) & 5 \\
\hline
\end{tabular}

(Sumber: Data Primer, 2021)

Tabel 5, menunjukkan waktu tunggu setiap pemesanan preform $600 \mathrm{ml}$ adalah 5 hari.

Penialaian waktu tunggu sesuai dengan dominasi hasil data primer dari perusahaan $\mathrm{X}$.

Tabel 6. Total Biaya Persediaan

\begin{tabular}{ccc}
\hline No & Jenis & Biaya/ tahun $(\mathrm{Rp})$ \\
\hline 1 & Preform $600 \mathrm{ml}$ (gross) & 439.845 .290 \\
\hline
\end{tabular}

(Sumber: Olah Data Primer, 2021)

Tabel 6, menunjukkan nilai biaya persediaan secara total sebesar Rp. 439.845.290.

Nilai biaya persediaan didapatkan dari komponen rata - rata permintaan, biaya penyimpanan, data selama 12 bulan dan biaya sekali pemesanan.

Tabel 7. Penilaian Re-Order Point

\begin{tabular}{cccccc}
\hline No & Jenis & $\begin{array}{c}\text { Permintaan rata }- \\
\text { rata (Gross) }\end{array}$ & Lead Time & $\begin{array}{c}\text { Re-Order } \\
\text { Point (gross) }\end{array}$ & $\begin{array}{c}\text { Re-Order } \\
\text { Point (buah) }\end{array}$ \\
\hline 1 & $\begin{array}{c}\text { Preform 600 } \mathrm{ml} \\
\text { (gross) }\end{array}$ & 183 & 0,200 & 15.862 & 2.284 .174 \\
\hline
\end{tabular}

(Sumber: Olah Data Primer, 2021)

Tabel 7, menunjukkan Re - Order Point sebesar 2.284.174 buah pada masa tahun mendatang yaitu dimulai bulan Agustus 2021- Juli 2022. Re - Order Point digunakan 
sebagai pemesanan kembali preform $600 \mathrm{ml}$ untuk melakukan persediaan digudang. Fungsi Re-Order Point untuk menghindari kurangnya persediaan di masa mendatang.

Tabel 8. Perbandingan Re-Order Point dengan Re-Order Point Eksisting

\begin{tabular}{ccccc}
\hline No & Jenis & ROP (buah) & $\begin{array}{c}\text { ROP Eksisting } \\
\text { (buah) }\end{array}$ & Selisih \\
\hline 1 & Preform $600 \mathrm{ml}$ (gross) & 2.284 .174 & 2.000 .000 & 284.174 \\
\hline
\end{tabular}

(Sumber: Olah Data Primer, 2021)

Tabel 8, menunjukkan perbandingan $R e-O r d e r$ secara eksisting dengan $R e-O r d e r$ Point secara metode analisis memiliki hasil pemesanan kembali yang berbeda. Re - Order Point penting di perhatikan oleh divisi logistik perusahaan. Peningkatan Re - Order Point berfungsi untuk meningkatkan laba perusahaan agar optimal dan mencapai laba yang dinamis. Kondisi Re - Order Point secara eksisting perusahaan sebesar 2.000.000 buah preform $600 \mathrm{ml}$ setiap melakukan pemesanan kembali. Dampak dari nilai eksisting konstan tidak mampu meningkatkan laba secara dinamis. Oleh sebab itu, dalam mencapai $R e-O r d e r$ Point yang optimum juga memerlukan indikator Green Logistic.

Re-Order Point secara metode analisis didapatkan sebesar 2.284.174 buah preform $600 \mathrm{ml}$. Capaian Re-Order Point secara metode analisis memerlukan indikator yang dapat meningkatkan kinerja Green Logistic tersebut.

Kegiatan metode analisis $R e$ - Order Point telah tercapai. Kemudian, langkah selanjutnya yaitu melakukan observasi mengenai permasalahan dengan menemukan indikator yang menjadi penghambat kinerja Green Logistic. Indikator Green Logistic menggunakan pendekatan FMEA (Failur Mode Effect Analysis). Indikator Green Logistic diidentifikasi dengan hasil sebagai berikut.

Tabel 9. Permasalahan Green Logistic Berdasarkan Indikator

\begin{tabular}{|c|c|c|c|c|c|}
\hline Permasalahan & $\begin{array}{c}\text { Indikator } \\
\text { Green } \\
\text { Logistic }\end{array}$ & Fungsi & $\begin{array}{l}\text { Function } \\
\text { Failure }\end{array}$ & Failure Mode & Cause \\
\hline $\begin{array}{l}\text { Peningkatan } \\
\text { Kinerja Green }\end{array}$ & & $\begin{array}{c}\text { Kegiatan } \\
\text { logistik ramah } \\
\text { lingkungan }\end{array}$ & $\begin{array}{c}\text { Kurang efektif } \\
\text { terkendala } \\
\text { lingkungan }\end{array}$ & $\begin{array}{c}\text { Emisi yang } \\
\text { membahayakan } \\
\text { lingkungan }\end{array}$ & $\begin{array}{c}\text { Monitoring } \\
\text { kegiatan } \\
\text { logistik }\end{array}$ \\
\hline $\begin{array}{c}\text { Logistic } \\
\text { dengan } \\
\text { Metode FMEA } \\
\text { guna }\end{array}$ & 15014000 & $\begin{array}{l}\text { Komitmen } \\
\text { strategi green } \\
\text { logistik }\end{array}$ & $\begin{array}{l}\text { Penerapan } \\
\text { belum } \\
\text { maksimal }\end{array}$ & $\begin{array}{c}\text { Minimnya } \\
\text { pemahaman ISO } \\
14000\end{array}$ & $\begin{array}{c}\text { Monitoring } \\
\text { kegiatan } \\
\text { logistik }\end{array}$ \\
\hline $\begin{array}{l}\text { meningkatkan } \\
\text { Re-Order }\end{array}$ & Warehouse & $\begin{array}{c}\text { Tempat } \\
\text { Penyimpanan }\end{array}$ & $\begin{array}{c}\text { Kurangnya } \\
\text { pemahaman } \\
\text { persediaan }\end{array}$ & $\begin{array}{c}\text { Persediaan } \\
\text { diluar jadwal }\end{array}$ & $\begin{array}{c}\text { Distribusi } \\
\text { tidak sesuai } \\
\text { jadwal }\end{array}$ \\
\hline
\end{tabular}


Point yang

Efektif

\begin{tabular}{|c|c|c|c|c|}
\hline & & $\begin{array}{c}\text { Konsep } \\
\text { persediaan } \\
\text { tidak } \\
\text { menggunakan } \\
\quad \text { tools }\end{array}$ & $\begin{array}{l}\text { Pengelolaan } \\
\text { jumlah } \\
\text { persediaan } \\
\text { kurang dari } \\
\text { standar }\end{array}$ & $\begin{array}{c}\text { Anggaran } \\
\text { produksi tidak } \\
\text { sesuai } \\
\text { implementasi }\end{array}$ \\
\hline & & $\begin{array}{c}\text { Titik } \\
\text { pemesanan } \\
\text { tidak sesuai }\end{array}$ & $\begin{array}{l}\text { Persediaan masa } \\
\text { mendatang tidak } \\
\text { mencapai target }\end{array}$ & $\begin{array}{c}\text { Merugikan } \\
\text { kegiatan } \\
\text { produksi }\end{array}$ \\
\hline & & $\begin{array}{c}\text { Pemesanan } \\
\text { persediaan } \\
\text { secara } \\
\text { eksisting } \\
\text { belum sesuai }\end{array}$ & $\begin{array}{c}\text { pemesanan } \\
\text { stagnan setiap } \\
\text { waktu }\end{array}$ & Laba stagnan \\
\hline $\begin{array}{l}\text { Sumber } \\
\text { Daya } \\
\text { Manusia }\end{array}$ & $\begin{array}{c}\text { Pelaku } \\
\text { Logistik }\end{array}$ & $\begin{array}{l}\text { Workshop } \\
\text { belum } \\
\text { dioptimalkan }\end{array}$ & $\begin{array}{l}\text { Perhitungan } \\
\text { logistik belum } \\
\text { tertata secara } \\
\text { metode }\end{array}$ & Laba stagnan \\
\hline
\end{tabular}

(Sumber: Olah Data Primer, 2021)

Tabel 9, menunjukkan indikator Green Logistic yang menjadi masalah yang terjadi di perusahaan. Kondisi yang ditemukan fokus pada logistik produk preform $600 \mathrm{ml}$. Indikator yang didapatkan selama observasi mendalam adalah ISO 14000, Warehouse dan Sumber Daya Manusia. Indikator ISO 14000 sebagai acuan logistik yang ramah lingkungan dan komitmen green logistik. Indikator Warehouse sebagai acuan konsep persediaan, titik pemesanan, perbandingan eksisting pemesanan dengan metode Re-Order Point. Indikator Sumber Daya Manusia sebagai acuan pelaku logistik dalam mencapai green logistik.

Tabel 10. Ranking Permasalahan Green Logistic Berdasarkan Indikator

\begin{tabular}{|c|c|c|c|c|c|c|c|c|}
\hline $\begin{array}{l}\text { Indikator } \\
\text { Green } \\
\text { Logistic }\end{array}$ & Fungsi & $\begin{array}{l}\text { Function } \\
\text { Failure }\end{array}$ & $\begin{array}{c}\text { Failure } \\
\text { Effect }\end{array}$ & $\begin{array}{c}\text { Severit } \\
y\end{array}$ & $\begin{array}{c}\text { Occuran } \\
\text { ce }\end{array}$ & $\begin{array}{c}\text { Detectio } \\
n\end{array}$ & RPN & Rank \\
\hline \multirow{2}{*}{ ISO 14000} & \multirow{2}{*}{$\begin{array}{c}\text { Kegiatan } \\
\text { logistik } \\
\text { ramah } \\
\text { lingkungan } \\
\text { Komitmen } \\
\text { strategi } \\
\text { green } \\
\text { logistik }\end{array}$} & $\begin{array}{c}\text { Kurang } \\
\text { efektif } \\
\text { terkendala }\end{array}$ & $\begin{array}{c}\text { Lingkungan } \\
\text { tercemar }\end{array}$ & 4 & 3 & 3 & 36 & 7 \\
\hline & & $\begin{array}{l}\text { Penerapan } \\
\text { belum } \\
\text { maksimal }\end{array}$ & $\begin{array}{c}\text { Lingkungan } \\
\text { organisasi } \\
\text { tidak sehat }\end{array}$ & 4 & 5 & 4 & 80 & 6 \\
\hline \multirow[b]{2}{*}{ Warehouse } & \multirow[b]{2}{*}{$\begin{array}{c}\text { Tempat } \\
\text { Penyimpan } \\
\text { an }\end{array}$} & $\begin{array}{c}\text { Kurangnya } \\
\text { pemahaman } \\
\text { persediaan }\end{array}$ & $\begin{array}{c}\text { Proses } \\
\text { Produksi } \\
\text { terhambat }\end{array}$ & 4 & 5 & 5 & 100 & 5 \\
\hline & & $\begin{array}{c}\text { Konsep } \\
\text { persediaan } \\
\text { tidak } \\
\text { menggunaka } \\
\text { n tools }\end{array}$ & $\begin{array}{c}\text { Anggaran } \\
\text { produksi } \\
\text { perusahaan } \\
\text { membengka } \\
\text { k }\end{array}$ & 6 & 5 & 7 & 210 & 3 \\
\hline
\end{tabular}




\begin{tabular}{|c|c|c|c|c|c|c|c|c|}
\hline & & $\begin{array}{l}\text { Titik } \\
\text { pemesanan } \\
\text { tidak sesuai }\end{array}$ & $\begin{array}{l}\text { Laba } \\
\text { perusahaan } \\
\text { menurun }\end{array}$ & 6 & 6 & 7 & 252 & 2 \\
\hline & & $\begin{array}{c}\text { Pemesanan } \\
\text { persediaan } \\
\text { secara } \\
\text { eksisting } \\
\text { belum sesuai }\end{array}$ & $\begin{array}{l}\text { Perusahaan } \\
\text { dalam } \\
\text { kondisi } \\
\text { stagnan pada } \\
\text { konsep laba }\end{array}$ & 7 & 6 & 7 & 294 & 1 \\
\hline $\begin{array}{l}\text { Sumber } \\
\text { Daya } \\
\text { Manusia }\end{array}$ & $\begin{array}{c}\text { Pelaku } \\
\text { Logistik }\end{array}$ & $\begin{array}{c}\text { Workshop } \\
\text { belum } \\
\text { dioptimalkan }\end{array}$ & $\begin{array}{l}\text { Perusahaan } \\
\text { dalam } \\
\text { kondisi } \\
\text { stagnan pada } \\
\text { konsep laba }\end{array}$ & 4 & 5 & 6 & 120 & 4 \\
\hline
\end{tabular}

(Sumber: Olah Data Primer, 2021)

Tabel 10, berdasarkan nilai severity, occurrence dan detection dilakukan ranking. Ranking 1, 2 dan 3 digunakan sebagai masalah yang harus di evaluasi dalam mencapai green logistic. Ranking 1 yaitu Pemesanan persediaan secara eksisting belum sesuai yang menjadi masalah dalam kondisi stagnan pada konsep laba. Ranking 2 yaitu Titik pemesanan tidak sesuai yang menyebabkan laba perusahaan menurun. Ranking 3 yaitu Konsep persediaan tidak menggunakan tools yang menyebabkan Anggaran produksi perusahaan membengkak.

Ketiga permasalahan green logistic paling kritis telah ditemukan. Ranking 1 dengan nilai RPN sebesar 294, ranking 2 dengan nilai RPN sebesar 252, ranking 3 dengan nilai RPN sebesar 210 .

Ketiga permasalahan green logistic diidentifikasi menggunakan Fishbone diagram untuk mengetahui akar permasalahan sesuai dengan faktor Equipment, Process, People, Materials, Environment dan Management.

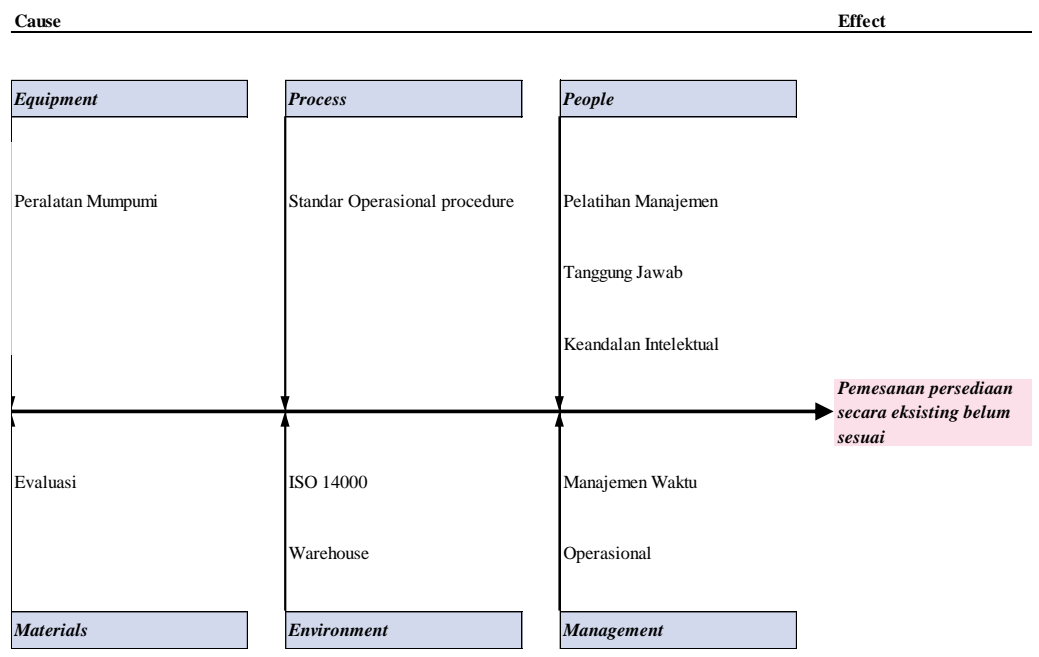

Gambar 1. Fishbone Diagram Pemesanan Persediaan Secara Eksisting Belum Sesuai 
Gambar 1, menunjukkan Fishbone Diagram pemesanan persediaan secara eksisting belum sesuai. Faktor paling dominan adalah people. Faktor people dengan sub faktor pelatihan manajemen, tanggung jawab dan keandalan intelektual.

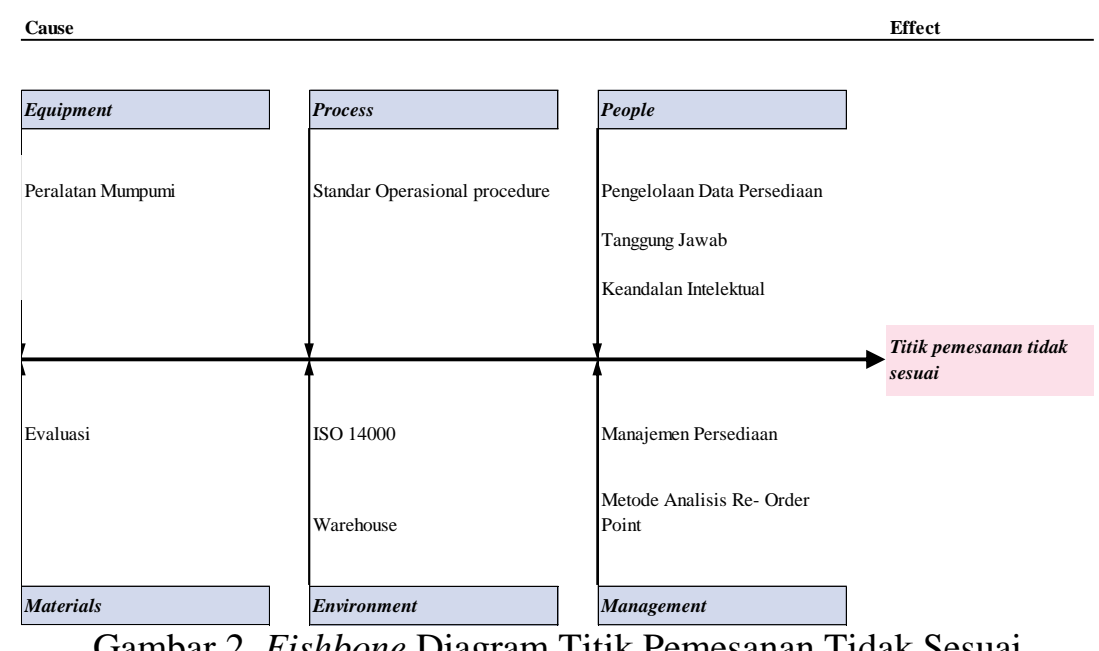

Gambar 2. Fishbone Diagram Titik Pemesanan Tidak Sesuai

Gambar 2, menunjukkan Fishbone Diagram titik pemesanan tidak sesuai. Faktor paling dominan adalah people. Faktor people dengan sub faktor pengelolaan data persediaan, tanggung jawab dan keandalan intelektual.

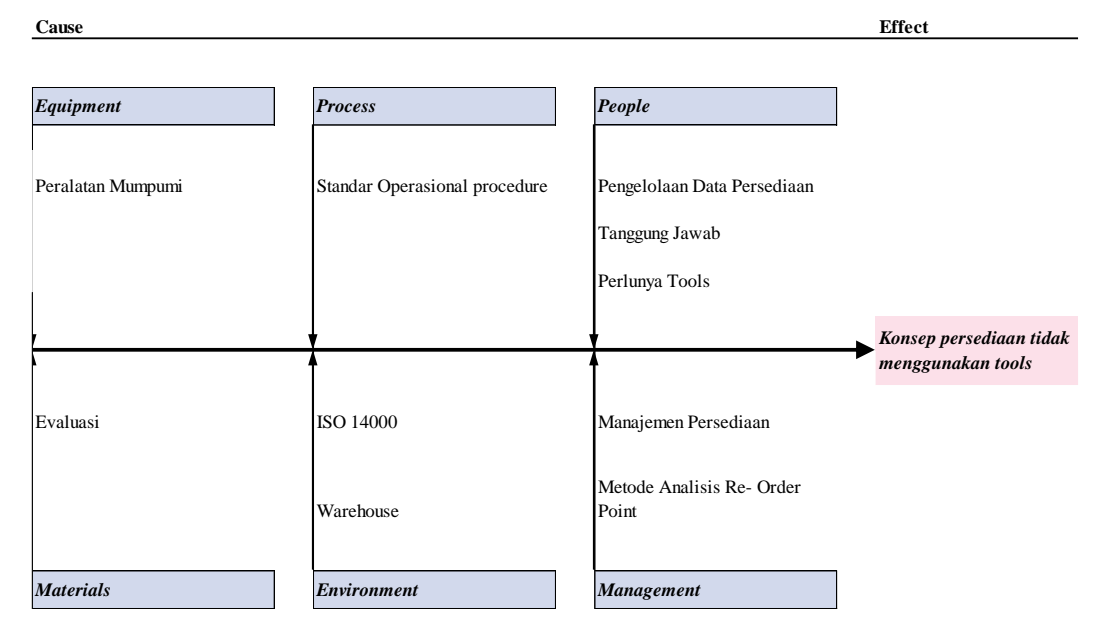

Gambar 3. Fishbone Diagram Konsep Persediaan Tidak Menggunakan Tools

Gambar 2, menunjukkan Fishbone Diagram Konsep Persediaan Tidak Menggunakan Tools. Faktor paling dominan adalah People. Faktor people dengan sub faktor pengelolaan data persediaan, tanggung jawab dan keandalan intelektual.

Tabel 11. Brainstrorming Ketiga Fishbone Diagram

\begin{tabular}{llllr}
\hline Atribut & Kemungkinan akar & Diskusi & Apakah & ini \\
Fishbone & masalah Green Logistic & menjadi & akar \\
Diagram & & masalah & Green \\
& & Logistic? & \\
\hline
\end{tabular}




\begin{tabular}{|c|c|c|c|}
\hline Equipment & $\begin{array}{l}\text { Tidak terdapat masalah, } \\
\text { karena equipment telah } \\
\text { mumpuni }\end{array}$ & $\begin{array}{l}\text { Peningkatan equipment } \\
\text { telah berhasil dan } \\
\text { memenuhi standar }\end{array}$ & Bukan \\
\hline Process & $\begin{array}{l}\text { Standar Operational } \\
\text { Procedure efektif } \\
\text { diterapkan }\end{array}$ & $\begin{array}{l}\text { Standar Operational } \\
\text { Procedure telah layak } \\
80 \% \text { dengan bukti audit } \\
\text { bulanan }\end{array}$ & Bukan \\
\hline People & $\begin{array}{l}\text { Penempatan kerja dan } \\
\text { tanggung jawab belum } \\
\text { optimal }\end{array}$ & $\begin{array}{l}\text { Pelatihan metode analisis } \\
\text { Re-Order Point sebagai } \\
\text { solusi }\end{array}$ & Ya \\
\hline Materials & $\begin{array}{l}\text { Evaluasi persediaan } \\
\text { belum sesuai metode } \\
\text { Re-Order Point }\end{array}$ & $\begin{array}{l}\text { Pelatihan metode analisis } \\
\text { Re-Order Point sebagai } \\
\text { solusi }\end{array}$ & Ya \\
\hline Environment & $\begin{array}{l}\text { Distribusi logistik } \\
\text { terjadi keterlambatan }\end{array}$ & $\begin{array}{l}\text { Pelatihan metode analisis } \\
\text { Re-Order Point sebagai } \\
\text { solusi }\end{array}$ & Ya \\
\hline Management & $\begin{array}{l}\text { Operasionalisasi } \\
\text { distribusi logistik dan } \\
\text { estimasi waktu belum } \\
\text { standar }\end{array}$ & $\begin{array}{l}\text { Berkaitan dengan People } \\
\text { mengenai Pelatihan } \\
\text { metode analisis } R e- \\
\text { Order Point sebagai } \\
\text { solusi }\end{array}$ & Ya \\
\hline
\end{tabular}

(Sumber : Olah data primer, 2021)

Tabel 12. Usulan Pengembangan Green Logistic

\begin{tabular}{|c|c|}
\hline $\begin{array}{c}\text { Akar Masalah Green } \\
\text { Logistic }\end{array}$ & Usulan Pengembangan Green Logistic \\
\hline $\begin{array}{l}\text { Penempatan kerja } \\
\text { dan tanggung jawab } \\
\text { belum optimal }\end{array}$ & $\begin{array}{l}\text { Monitoring dan pelatihan pekerja di bidang logistik perlu di } \\
\text { tingkatkan. Pelatihan dapat dilakukan setiap } 1 \text { bulan sekali. } \\
\text { Pelatihan ini berguna membekali pekerja di bidang logistik paham } \\
\text { tentang green logistic. Green logistic yang diharapkan mengenai } \\
\text { Re-Order Point yang sesuai dengan metode analisis. Penggunaan } \\
\text { Re - Order Point secara eksisting akan mempermudah pekerja. } \\
\text { Tetapi, ini sebagai masalah karena laba tidak dapat meningkat. }\end{array}$ \\
\hline $\begin{array}{l}\text { Evaluasi persediaan } \\
\text { belum sesuai metode } \\
\text { Re-Order Point }\end{array}$ & $\begin{array}{l}\text { Evaluasi persediaan menggunakan metode analisis Re -Order } \\
\text { Point sebesar } 2.284 .174 \text { buah Preform } 600 \mathrm{ml} \text {. Sedangkan secara } \\
\text { eksisting konstan sebesar } 2.000 .000 \text { buah preform } 600 \mathrm{ml} \text {. Selisih } \\
\text { yang didapatkan sebesar } 284.174 \text { buah Preform } 600 \mathrm{ml} \text {. }\end{array}$ \\
\hline $\begin{array}{l}\text { Distribusi logistik } \\
\text { terjadi keterlambatan }\end{array}$ & $\begin{array}{l}\text { Keterlambatan kedatangan preform } 600 \mathrm{ml} \text { menyebabkan } \\
\text { persediaan di gudang kehabisan stok. Sehingga, kegiatan proses } \\
\text { produksi akan menjadi hambatan. Hambatan inilah juga } \\
\text { berpengaruh terhadap anggaran yang tidak sesuai dengan } \\
\text { implementasi dilapangan. Sehingga, optimasi jadwal kedatangan } \\
\text { harus di meeting dengan sumber daya manusia yang berkaitan } \\
\text { dengan divisi logistik. }\end{array}$ \\
\hline
\end{tabular}

(Sumber: Olah data penelitian, 2021) 


\section{KESIMPULAN}

Kesimpulan penelitian ini 1) Perbandingan nilai pemesanan kembali secara eksisting sebesar 2.000.000 buah preform 600ml sedangkan metode Re-Order Point sebesar 2.284.174 pada Preform Clear $600 \mathrm{ml}$, sehingga efektifitas laba dengan acuan Re-Order Point lebih menguntungkan, 2) Peran Green Logistic pada Preform Clear $600 \mathrm{ml}$ dengan usulan pengembangan Monitoring dan pelatihan pekerja di bidang logistik perlu di tingkatkan 1 bulan, evaluasi persediaan lebih baik menerapkan metode analisis $R e-O r d e r$ Point dan meningkatkan jadwal kedatangan preform $600 \mathrm{ml}$ dengan langkah meeting prakedatangan preform $600 \mathrm{ml}$.

Penelitian ini memiliki lingkup manajemen persediaan preform $600 \mathrm{ml}$ di PT. X yang meningkatkan kinerja dengan langkah green logistic. Metode analisis menggunakan $R e-$ Order Point, FMEA dan Fishbone Diagram mengenai usulan pengembangan green logistic.

Bagi peneliti selanjutnya, dapat mengembangkan dalam lingkup pendekatan DMAIC sebagai pengembangan green logistic yang lebih kompleks.

\section{UCAPAN TERIMA KASIH}

Ucapan terima kasih kepada Universitas Kadiri dan Universitas Pancasakti Tegal yang khususnya pada program studi Teknik Industri masing - masing yang mendukung kegiatan penelitian ini.

\section{DAFTAR PUSTAKA}

Anik Satria Dewi, N., Mulyani, S., \& Arnata, I. (2016). Pengendalian Kualitas Atribut Kemasan Menggunakan Metode Failure Mode Effect Analysis (Fmea)Pada Proses Produksi Air Minum Dalam Kemasan. Jurnal Rekayasa Dan Manajemen Agroindustri, 4(3), $149-160$.

Badariah, N., Surjasa, D., Trinugraha, Y., \& Industri, J. T. (2012). Analisa Supply Chain Risk Management Berdasarkan Metode Failure Mode and Effects Analysis (Fmea). Jurnal Teknik Industri, 2(2), 110-118. https://www.trijurnal.lemlit.trisakti.ac.id/tekin/article/view/7021

Braaksma, A. J. J. (2012). Asset information for FMEA-based maintenance [University of Groningen]. In Faculty of Economics and Business. http://hdl.handle.net/11370/ef38be1a-5fb1-4ecd-b39b-1b2dc0d39978

Fachry Hafid, M., \& Muh Syukur Yusuf, A. (2018). Analisis Penerapan Quality Control Circle Untuk Meminimalkan Binning Loss Pada Bagian Receiving Pt. Hadji Kalla Toyota Depo Part Logistik Makassar. Journal of Industrial Engineering Management, 3(2), 1. https://doi.org/10.33536/jiem.v3i2.228

Hamdy, M. I., \& Masari, A. (2020). Penerapan Re Order Point (ROP) dan Safety Stock pada Pengadaan Chemical Demulsifier dan Chemical Reverse Demulsifier. Jurnal Teknik 
Industri: Jurnal Hasil Penelitian Dan Karya Ilmiah Dalam Bidang Teknik Industri, 5(2), 87. https://doi.org/10.24014/jti.v5i2.8998

Hertini, E., Anggriani, N., Mianna, W., \& Supriatna, A. K. (2018). Economic Order Quantity (EOQ) Optimal Control Considering Selling Price and Salesman Initiative Cost. IOP Conference Series: Materials Science and Engineering, 332(1). https://doi.org/10.1088/1757-899X/332/1/012013

Hudori, M. (2018). Formulasi Model Safety Stock dan Reorder Point untuk Berbagai Kondisi Persediaan Material. Jurnal Citra Widya Edukasi, 10(3), 217-224. https://journal.cwe.ac.id/index.php/jurnal_citrawidyaedukasi/article/view/109/98

Indrasari, L. D. (2020). Penerapan Single Exponential Smoothing (SES) dalam Perhitungan Jumlah Permintaan Air Mineral Pada PT. Akasha Wira International. JATI UNIK: Jurnal Ilmiah Teknik Dan Manajemen Industri, 3(2), 87-98.

Indrasari, L. D., Nursanti, E., \& Vitasari, P. (2014). MODEL STRATEGI GREEN LOGISTIC ( PENYIMPANAN ) PADA PERUSAHAAN MODAL ASING PT. XYZ. Engineering - Jurnal Bidang Teknik Fakultas Teknik Universitas Pancasakti Tegal.

Ivanov, D., Tsipoulanidis, A., \& Schönberger, J. (2017). Production and Material Requirements Planning. In Global Supply Chain and Operations Management: A Decision-Oriented Introduction to the Creation of Value (pp. 317-343). Springer International Publishing. https://doi.org/10.1007/978-3-319-24217-0_12

Mangla, S. K., Luthra, S., \& Jakhar, S. (2018). Benchmarking the risk assessment in green supply chain using fuzzy approach to FMEA: Insights from an Indian case study. Benchmarking, 25(8), 2660-2687. https://doi.org/10.1108/BIJ-04-2017-0074

Nobil, A. H., Sedigh, A. H. A., \& Cárdenas-Barrón, L. E. (2020). Reorder point for the EOQ inventory model with imperfect quality items. Ain Shams Engineering Journal, 11(4), 1339-1343. https://doi.org/10.1016/j.asej.2020.03.004

Nugroho, A. J. (2017). Evaluasi Gangguan Jaringan Telepon dengan Kombinasi Metode Fault Tree Analysis dan Failure Mode And Effect Analysis. Jurnal Ilmiah Teknik Industri, 16(2), 88. https://doi.org/10.23917/jiti.v16i2.2420

Prokop, D. (2011). Green logistics and supply chain management. In Green Finance and Sustainability: Environmentally-Aware Business Models and Technologies. https://doi.org/10.4018/978-1-60960-531-5.ch020

Seroka-Stolka, O. (2014). The Development of Green Logistics for Implementation Sustainable Development Strategy in Companies. Procedia - Social and Behavioral Sciences, 151, 302-309. https://doi.org/10.1016/j.sbspro.2014.10.028

Sutrisno, A., \& Lee, T. (2011). Service reliability assessment using failure mode and effect analysis (FMEA): survey and opportunity roadmap. International Journal of Engineering, Science and Technology, 3(7), 25-38. https://doi.org/10.4314/ijest.v3i7.3s

Trivellas, P., Malindretos, G., \& Reklitis, P. (2020). Implications of green logistics management on sustainable business and supply chain performance: evidence from a survey in the greek agri-food sector. Sustainability (Switzerland), 12(24), 1-29. https://doi.org/10.3390/su122410515 
Umry, T. F., \& Singgih, M. L. (2019). Inventory Management and Reorder Point (ROP) Strategy Using ABC Analysis Methods in Textile Manufacture. IPTEK Journal of Proceedings Series, O(5), 358. https://doi.org/10.12962/j23546026.y2019i5.6355

Waisul, F., Rusmana, K., \& Hidayat, S. (2017). ANALISIS HAMBATAN DAN REKOMENDASI SOLUSI PADA PROSES OUTBOUND LOGISTIC PT XYZ DENGAN SEVEN TOOLS DAN FMEA. Seminar Nasional Inovasi Dan Aplikasi Teknologi Di Industri 2017, 1-5. 